\title{
CRIME E CASTIGO: O SER HUMANO COMO INIMIGO
}

Camilla Isabely Gomes da Silva Membro do Grupo de Estudos Edgar Morin Membro do Grupo de Extensão Assistência Jurídica e Acompanhamento Sociofamiliar aos Apenados da Colônia Penal Agrícola de Sousa-PB Email: camilla.isabely@ hotmail.com

Resumo:Apresenta-se a teoria do Direito Penal do Inimigo de forma a contra argumentá-la por meio de uma discussão acerca da condição humana e dos Direitos Humanos, o que é feito por meio de uma revisão bibliográfica. $\mathrm{O}$ ser humano ao infringir normas não se afasta de sua humanidade, pois o desvio é inerente a espécie.

Palavras-chave: Direito Penal. Direitos Humanos. Condição Humana. 


\title{
1 INTRODUÇÃO
}

A teoria do Direito Penal do Inimigo é defendida por Jakobs, e vem se disseminando no mundo moderno a mais de duas décadas. Essa teoria busca a prática de um Direito Penal capaz de distinguir os infratores em duas vertentes: os delinquentes e os criminosos, de forma que os primeiros tenham resguardados o seu status de cidadão e, uma vez que infrinjam a lei, tenham ainda protegido seu direito ao julgamento de acordo com o ordenamento jurídico estabelecido e a ser reintegrado à sociedade; os outros, no entanto, seriam denominados inimigos do Estado e a estes restariam tratamento rígido e diferenciado (JAKOBS, 2007).

Tem-se o objetivo de apresentar a condição humana como forma de unificação do ser humano, isso através da apresentação do conceito de condição humana de Morin, de forma que seja possível compreender que o ser humano possui em si a inteligência e a demência, ou seja todos somos capazes de cometer atrocidades e sermos bondosos, pois o ser humano é complexo e inconstante (MORIN, 2003).

A pesquisa será realizada por meio da análise teórica, ou seja: "dedicada a reconstruir teoria, conceitos, ideias, ideologias, polêmicas, tendo em vista, em termos imediatos, aprimorar fundamentos teóricos". (DEMO, 2000, P. 20). Esse modelo de pesquisa é fundado na reconstrução das teorias, quadros de referência, condições explicativas da realidade, polêmicas e discussões pertinentes. A pesquisa teórica não implica imediata intervenção na realidade, mas seu papel é decisivo na criação de condições para a intervenção. Desenvolvida com base em material já elaborado, constituído principalmente de livros e artigos científicos:

\begin{abstract}
A pesquisa bibliográfica é feita a partir do levantamento de referências teóricas já analisadas, e publicadas por meios escritos e eletrônicos, como livros, artigos científicos, páginas de web sites. Qualquer trabalho científico inicia-se com uma pesquisa bibliográfica, que permite ao pesquisador conhecer o que já se estudou sobre o assunto. Existem, porém, pesquisas científicas que se baseiam unicamente na pesquisa bibliográfica, procurando referências teóricas publicadas com o objetivo de recolher informações ou conhecimento prévios sobre o problema a respeito do qual se procura a resposta. (FONSECA, 2002, P.32).
\end{abstract}

Será discutido acerca da Teoria do Direito Penal do Inimigo, de forma a apresentar contrapontos no que se refere a condição humana e aos Direitos Humanos a fim de demonstrar que ao infringir normas o ser humano não se afasta de sua humanidade, a fim de suscitar a discussão acerca do Direito Penal do Inimigo, visto que há ampla discussão embasada no avanço da tese ora citada no ordenamento jurídico brasileiro, principalmente, quando há pressão da mídia e comoção social relacionado à determinado assunto penal (LEMES, 2003). 


\section{DIREITO COMO GARANTIA DO BOM CONVÍVIO}

Ao analisarmos a formação do Direito, tem-se que o homem não existe sem o Direito e o Direito não sem existe sem o homem:

Entende-se, em sentido comum, o Direito como sendo o conjunto de normas para a aplicação da justiça e a minimização de conflitos de uma dada sociedade. Estas normas, estas regras, esta sociedade não são possíveis sem o Homem, porque é o Ser Humano quem faz o Direito e é para ele que o Direito é feito. (CASTRO, 2007, P. 2)

O Direito surge a fim de garantir a manutenção da vida em sociedade, considerando a complexidade humana, buscando moldá-la para que a sociedade prospere (CASTRO, 2007).

Sendo assim, o Direito surge com o objetivo de manter o bom convívio em meio social. Dessa forma, tem-se que o reconhecimento de direitos humanos, assim como a positivação dos direitos fundamentais, somente foi possível por meio da evolução histórica, ou seja, tais direitos não surgiram todos prontos de uma vez, mas foram sendo desvendados, declarados e construídos conforme as próprias transformações da civilização humana, sendo a luta pela limitação do poder político um dos principais fatores para o acolhimento destes direitos (COMPARATO, 2005).

\section{DIREITO PENAL DO INIMIGO}

Deve existir dois tipos de direito: um primeiro qual é assegurado ao cidadão que mesmo violando um preceito recebe a oportunidade de "reconhecer" a vigência deste através da liquidação de uma pena. De forma que ao ser punido ainda possa ser reconhecido como cidadão pelo Estado, e possua seus direitos de cidadão assegurados (JAKOBS, 2007).

No entanto, uma outra forma de Direito surge, o Direito Penal do Inimigo, o qual reserva-se aos indivíduos que por seu comportamento, ocupação ou práticas, ou seja: "se tem afastado, de maneira duradoura, ao menos de modo decidido, do Direito, isto é, que não proporciona a garantia cognitiva mínima necessária a um tratamento como pessoa", devendo serem tratados como inimigos (JAKOBS, 2007, P.35).

Há, inicialmente, a distinção entre o conceito de pessoa e o de indivíduo, ou seja: pessoa será aquela que esteja envolvida com a sociedade, sendo um sujeito de direitos e 
obrigações dentro do Estado; por sua vez o indivíduo, será um ser sensorial, pertencente à ordem natural, movendo-se inteligentemente, por suas satisfações e insatisfações de acordo com suas preferências e interesses, negligenciando-se, ignorando a forma como comporta-se a sociedade na qual se insere (JAKOBS, 2007).

Ao delinquir, o cidadão terá o seu direito a um processo legal devido, de forma que suas garantias fundamentais sejam asseguradas, recebendo ao fim do processo uma pena como coação pelo ato ilícito cometido. O inimigo por ser considerado como um perigo a ser combatido, devendo o Direito antever ao efetivo cometimento de um crime, considerando desde início sua periculosidade, ou seja: "o Direito penal do inimigo é daqueles que o constituem contra o inimigo: frente ao inimigo é só coação física, até chegar à guerra" (JAKOBS, 2007, P.30).

Assim tem-se que a periculosidade do agente servirá como forma de distinção daquele a ser considerado como inimigo, ao qual contrapõe-se ao cidadão. $\mathrm{O}$ cidadão ao delinquir apesar de ir de encontro ao direito, tem uma personalidade voltada ao ordenamento jurídico devendo ser punido segundo sua culpabilidade, à medida que o inimigo deve ser combatido segundo sua periculosidade. Não há vistas há uma conduta realizada, ou tentada, mas pressupõe-se o âmbito interno do indivíduo, o perigo de dano futuro à vigência da norma (JAKOBS, 2007).

O Direito Penal do Inimigo apresenta-se através de três elementos: se constata um amplo adiantamento da punibilidade; as penas previstas são desproporcionalmente altas; determinadas garantias processuais são relativizadas ou, inclusive, suprimidas.

A proposta de Jakobs afasta o direito ao devido processo legal e adequado às garantias do indivíduo, o que culmina em um verdadeiro procedimento de combate ao inimigo declarado; ideia que não se adequa com aquilo que é defendido pelo Estado Democrático de Direito, justamente por suas bases em princípios e garantias que viabilizam o pleno exercício do contraditório e da ampla defesa durante a persecução criminal (JAKOBS, 2007).

Com a ascensão de Hitler ao poder, o Estado iniciou um processo de reorganização, isso com base em critérios duvidosos, o que culminou, no ano de 1944, na edição do projeto nacional-socialista sobre o tratamento dos "estranhos à comunidade" (GRECO, 2011):

Tal projeto, considerado como um dos mais terríveis da história do Direito Penal, propunha, dentre outras coisas: a) a castração dos homossexuais; b) a prisão por tempo indeterminado dos considerados associais, ou seja, pessoas que tivessem um comportamento anti-social, a exemplo dos vadios, prostitutas, alcoólatras, praticantes de pequenas infrações penais, etc., sem que houvesse necessidade, 
inclusive, de que tivessem praticado qualquer delito; c) a esterilização, a fim de evitar a propagação daqueles considerados associais e inúteis para a sociedade. (GRECO, 2011, P. 26-27)

Os campos de concentração não foram apenas destinados ao extermínio de pessoas e à degradação de seres humanos: serviram também para a horrível experiência que consiste em eliminar, em condições cientificamente controladas, a própria espontaneidade enquanto expressão do comportamento humano, e em transformar a personalidade humana em simples coisa, em alguma coisa que nem mesmo os animais possuem (ARENDT, 2012).

Enfim, medidas que fogem completamente daquilo que é defendido pelo princípio da dignidade da pessoa humana, justamente por desconsiderá-la como pessoa.

\title{
4 CONDIÇÃO HUMANA EM CRIME E CASTIGO
}

Apenas a espécie humana é capaz de criar história e construir utopias, sendo assim, a sociedade desenvolve-se fundamentada no compartilhamento de linguagem,por meio das interações humanas(ALMEIDA, 2014). Essa capacidade de criar narrativas diferencia a espécie humana dos demais animais. O inconsciente humano aproxima essa espécie dos animais, pois, assim como o inconsciente age nos animais, controlando suas ações, ele também é responsável pelo controle de parte das ações humanas. Essas narrativas são o meio que a espécie humana encontra para ordenar e construir significados, sejam eles científicos ou não, pois a ciência é a narrativa dos acontecimentos(ALMEIDA, 2014).

A espécie humana desenvolve-se, no decorrer dos anos, tornando-se capaz de criar:

\begin{abstract}
A condição humana é, portanto, um caso particular da sucessão de três macro histórias que se hibridam. Ela imprime e tatua sobre o lítio das estrelas, sobre as histórias da matéria e da vida as criações da cultura: regras, valores, a narrativa, o sonho, a ilusão, a mentira. É curioso esse último atributo humano - a mentira. Nós somos os únicos animais que sabemos mentir. É uma criação absolutamente humana. (ALMEIDA, 2014, P.79):
\end{abstract}

A condição humana apresenta-se inacabada, pois o ser humano é um ser dotado de complexidade e inconstâncias, fato possível de ser observado por meio de uma análise acerca da construção histórica humana.

A espécie humana, diferentemente das demais espécies que povoam o planeta, desenvolve-se de forma a alcançar o patamar de um ser complexo, ser este dotado de paradoxos, inconstâncias e incertezas, que tem em si o amor e ódio, tristeza e alegria, crença e descrença: 
O ser humano é um ser racional e irracional, capaz de medida e desmedida; sujeito de afetividade intensa e instável. Sorri, ri, chora, mas sabe também conhecer com objetividade; é sério e calculista, mas também ansioso, angustiado, gozador, ébrio, extático; é um ser de violência e de ternura, de amor e de ódio; é um ser invadido pelo imaginário e pode reconhecer o real, que é consciente da morte, mas que não pode crer nela; que secreta o mito e a magia, mas também a ciência e a filosofia; que é possuído pelos deuses e pelas Idéias, mas que duvida dos deuses e critica as Idéias; nutre-se dos conhecimentos comprovados, mas também de ilusões e de quimeras. (MORIN, 2000, p. 59).

Ao estudar as obras de Edgar Morin, observa-se a possibilidade de compreensão da complexidade humana por meio da análise das obras do escritor russo Dostoiévski, que cria e descreve seus personagens demonstrando sua humanidade e, consequentemente, sua complexidade. Aqui se exemplifica a complexidade humana por meio da obra "Crime e Castigo", onde o autor demonstra cada aspecto da realidade de Raskólnikov, com o intuito de expor ao leitor todas as dimensões do personagem, a partir de diferentes ângulos de percepção(DOSTOIÉVSKI, 2010).

Baseado na análise profunda do comportamento do protagonista, com relação às suas experiências, o autor (DOSTOIÉVSKI, 2010) demonstra, a partir das alterações emocionais e de caráter deste, os motivos que justificam suas atitudes e sua forma de compreender o mundo. Sua intenção está longe de querer retratar a bem-sucedida adaptação do indivíduo à sociedade. Uma vez que o ser humano, como ser complexo, tem em si a razão, a afetividade e a pulsão, que atuam de forma antagônica e concorrente, pois a afetividade pode, por exemplo, ser o propulsor de uma pulsão homicida passional que será fundamentada e justificada pela razão, (MORIN, 2000).

Quando descreve a reação de Raskólnikov, enquanto este se prepara para cometer o homicídio contra a usurária - pelo fato de não encontrar alternativa para sua situação miserável, o autor coloca o protagonista em um duelo entre o que ele é e o que ele precisa fazer para sobreviver. Um conflito constante na narrativa que permeia toda a obra é a incerteza entre o que é necessário e o que é permitido naquela sociedade. $O$ autor (DOSTOIÉVSKI, 2010) constrói um personagem central, dotado da complexidade inerente à condição humana, pois esse não é um criminoso nato: é um ser humano, esmagado pela miséria, sem perspectiva de dias melhores. Dessa forma, a trama põe em questão o caráter da personagem em contraponto com seu comportamento:

Senhor, poderá ser, mas será que posso pegar, de verdade, num machado para esmigalhar-lhe o crânio? Será possível que eu possa lavar-me em sangue quente, viscoso, que eu force uma fechadura, roube, trema e me esconda todo ensanguentado [...] com o machado? Mas meu Deus, isso será possível? (DOSTOIÉVSKI, 2010, P.88). 
Quando o protagonista mata a usurária, vislumbra-se a dualidade humana (MORIN, 2003), o homo demense o homo sapiens (de forma que o humano se manifesta ora com sabedoria admirável, ora com uma insensatez inesperada), são esses complementares e ao mesmo tempo opostos, apresentam-se em conflito, mas fazem parte da condição humana. Em pequenos intervalos de tempo, sua lucidez dá lugar a uma espécie de demência. É como se a personagem perdesse o controle sobre sua própria consciência. Por meio da utilização do discurso indireto livre, o autor possibilita ao narrador mostrar tanto o que a personagem fala quanto o que ele pensa, de modo que é possível ter acesso a todos as nuances de seu raciocínio. Assim, quando o protagonista tenta limpar seu machado em um pano vermelho, a fim de que o sangue não apareça, o narrador apresenta o pensamento de alguém que está aparentemente calmo. No entanto, em seguida, nota-se que Raskólnikov passa a se preocupar com a possibilidade de loucura e parece estar transtornado:

Começou por limpar as mãos ensanguentadas no pano vermelho. "É vermelho: o sangue deve ser menos visível sobre vermelho", pensou e, de súbito, conteve-se: "Senhor, será que enlouqueci?", conjeturou, amedrontado. (DOSTOIÉVSKI, 2010, P. 113).

Explorando as dobras da consciência do protagonista - Raskólnikov, (DOSTOIÉVSKI, 2010), consegue construir um personagem tão humano e complexo como qualquer um de seus leitores. Alguém que está sempre se equilibrando entre as escolhas e as consequências; que tenta justificar os meios pelo fim; que vive atormentado pelo que acredita e pela forma como as coisas são tratadas na sua sociedade; que já não consegue vislumbrar a tênue diferença: o lícito e o conveniente, entre a razão e a loucura. Enfim, a exemplificação da condição humana, a descrição do ser humano dotado de vícios e virtudes.

No que se refere à esfera individual (MORIN, 2010), todo ser humano possui particularidades e universalidades, isso quanto ao desenvolvimento cerebral, mental, psicológico, afetivo, intelectual e subjetivo.

Raskólnikov, do ponto de vista da esfera individual, contradiz a "harmonia com o universo": é pobre, ambicioso, é impiedoso, ao mesmo que tempo age com muita piedade; às vezes se comporta como uma boa pessoa e outras com nenhuma bondade; por vezes é egoísta, outras vezes é imensamente generoso. Do ponto de vista da universalidade, vislumbra-se que ele não é mau nem bom, ele tem ambas as características, como todos os seres humanos, um misto de bondade e maldade convivendo em constante conflito. É essa simultaneidade de comportamento e de caráter que faz com que a personagem central da trama seja sentida pelo leitor não apenas como personagem de ficção, mas como um ser humano(DOSTOIÉVSKI, 
2010).

O indivíduo, a espécie e a sociedade são indissociáveis (MORIN, 2000), pois não haverá espécie sem indivíduos e não haverá sociedade sem espécie, uma vez que a sociedade se desenvolverá por meio do agrupamento de indivíduos que formam a espécie. Na narrativa apresentada pelo autor, é possível observar um personagem principal, um indivíduo dotado da complexidade inerente à espécie humana, que é fruto da sociedade, mas que possui características que também são formadoras desta. Desse agrupamento surgem as interações humanas que darão vida à cultura e à auto-organização da sociedade, esta que dará forma ao direito, visto que o direito surge com o advento da sociedade, como será visto posteriormente, ou seja: “[...] todo desenvolvimento verdadeiramente humano significa o desenvolvimento conjunto das autonomias individuais, das participações comunitárias e do sentimento de pertencer à espécie humana" (MORIN, 2000, P.56).

\section{DIREITOS HUMANOS}

O conceito de Direitos Humanos é dotado de universalidade (PIOVESAN, 2006), pois possui extensão universal, e basta possuir condição de pessoa para ser titular de direitos. Para a autora, o ser humano é visto como um ser essencialmente moral com unicidade existencial e dignidade.

As atrocidades cometidas durante a Segunda Guerra Mundial alertaram a comunidade internacional para a necessidade de proteção dos Direitos Humanos como uma questão de legítimo interesse e preocupação internacional (PIOVESAN, 2009). Conforme os Direitos Humanos transcendem o domínio do Estado ou aquilo que se tem por competência exclusiva da nação. A junção desses fatos culminou no desenvolvimento de um código comum de ação, dotado de parâmetros globais de ação estatal, aos quais os Estados devem se adequar, no sentido de promover e proteger os direitos humanos.

Conforme a mesma autora, tal fato fez-se necessário, pois os regimes totalitários significaram a ruptura do paradigma dos Direitos Humanos, uma vez que se negou o valor de pessoa humana como fonte de direito. Assim, surgiu a necessidade de reestruturar os Direitos Humanos, como referencial e paradigma ético que reaproxime o direito e a moral, ou seja, o direito a ter direitos (ARENDT, 1972). Assim, a Segunda Guerra surge como marco na ruptura com os Direitos Humanos e o pós-guerra advém como reconstrução desses direitos: 
[...] após três lustros de massacres e atrocidades de toda sorte, iniciados com o fortalecimento do totalitarismo estatal nos anos 30, a humanidade compreendeu, mais do que em qualquer outra época da história, o valor supremo da dignidade humana. O sofrimento como matriz da compreensão do mundo e dos homens, segundo a lição luminosa da sabedoria grega, veio a aprofundar a afirmação histórica dos direitos humanos. (COMPARATO 2005, P. 54)

Como visto anteriormente, no decorrer da história humana, as várias civilizações e povos possuíam suas próprias concepções de direitos humanos, no entanto, após a Segunda Guerra, teve início o processo de internacionalização dos Direitos Humanos. Esse processo de internacionalização possuiu duas vertentes, restringindo a soberania do Estado, uma vez que esse passou a ser um dos principais violadores dos Direitos Humanos e atuando na universalização desses direitos a fim de que sejam estendidos a todos.

Como exemplo de limitação da soberania estatal é possível citar o Tribunal de Nuremberg,definido como um tribunal militar com competência para julgar os casos de crimes de guerra e crimes contra a humanidade perpetrados pelas antigas autoridades políticas e militares da Alemanha nazista e do Japão imperial, surgindo entre os anos de 1945 e 1946, e possui grande relevância para o fortalecimento dos direitos humanos e dos direitos fundamentais no plano internacional (COMPARATO, 2005 e FACHIN, 2009). Esse Tribunal não apenas consolida a ideia da necessidade de limitação da soberania Estatal, como também reconhece que os indivíduos têm direitos protegidos pelo direito internacional (PIOVESAN, 2009).

Como marco inicial de uma nova ordem internacional dos Direitos Humanos de forma universal, tem-se a assinatura da Carta das Nações Unidas (FACHIN, 2009). Uma vez que instaurou um novo modelo de comportamento nas relações entre nações, que fulminam o desenvolvimento de relações amistosas entre Nações (PIOVESAN, 2009), a cooperação internacional no plano econômico, social e cultural, a adoção de um padrão internacional de saúde, a proteção ao meio ambiente, a criação de uma nova ordem econômica global e a proteção internacional dos direitos humanos:

[...] no período do pós-Guerra Fria, os direitos humanos continuam a ser um terreno de conflitos entre concepções diferentes do que são esses direitos, e sobre as condições da sua aplicação e das sansões à sua violação. No momento presente, estamos a entrar numa nova fase desses conflitos: por um lado, parece desenhar-se uma tendência, por parte de alguns Estados e, em particular, da única potência global, os Estados Unidos, para subordinar a defesa dos direitos humanos aos seus imperativos estratégicos, justificados pela ,guerra contra o terrorismo ${ }^{\text {ee }} \mathrm{e}$, mais recentemente, pelo uso da ,guerra preventiva"e contra aqueles que forem considerados como ameaças reais ou potenciais aos seus interesses e à sua segurança. (NUNES, 2004, P.17):

Conforme o contexto histórico formado pós-guerra, tem-seque umas das causas da 
classificação dos Direitos Humanos como direitos coletivos foi a criação de Estados, em que passaram a residir grupos heterogêneos, que não pertenciam a uma única nacionalidade, por força de suas diferenciações linguísticas, étnicas e religiosas (LAFER, 1998).

É nesse tecer junto que se desenvolve a reconstrução dos Direitos Humanos, como paradigma referencial ético a orientar a ordem internacional contemporânea e que critica e repudia a concepção positivista de um ordenamento jurídico que se afasta dos valores éticos, preso ao mero formalismo jurídico, isso considerando que o nazismo e o fascismo ascenderam ao poder dentro da legalidade e promoveram a barbárie em nome e sob proteção da lei (PIOVESAN, 2009).

Esse período foi dotado de incertezas e não se podia prever o amanhã:

Todos os grandes acontecimentos do século - a deflagração da Primeira Guerra Mundial, a Revolução Soviética no império czarista, as vitórias do comunismo e do nazismo, o golpe teatral do pacto germânicosoviético, de 1939, a derrota da França, as resistências de Moscou e Stalingrado - foram inesperados; até o inesperado de 1989: a queda do muro de Berlim, o colapso do império soviético, a guerra da Iugoslávia. Hoje estamos em Escuridão e bruma, e ninguém pode predizer o amanhã. (MORIN, 2003, P. 61).

Faz-se necessário ter consciência da história para que a humanidade seja ser capaz de identificar aquilo que é possível acontecer no que se refere ao destino humano, mas também para que estejam abertas as incertezas do futuro (MORIN, 2003). Pois, dessa forma, será possível preparar-se para um mundo terreno de incertezas e aguardar o inesperado advém do destino humano.

\section{CONCLUSÃO}

Quem são os inimigos? Alguns, de pronto, responderiam: os traficantes de drogas, os terroristas, as organizações criminosas os assassinos, estupradores... E quem mais? Quem mais poderia enquadrar-se como inimigo? É certo que essa lista poderá nunca ter fim. Aquele que estiver no poder, amparado pelo raciocínio do Direito Penal do Inimigo, poderá afastar o seu rival político sob o argumento da sua falta de patriotismo por atacar as posições governamentais. Outros poderão concluir que também é inimigo o estuprador de sua filha. Ou seja, dificilmente se poderá encontrar um conceito de inimigo, nos moldes pretendidos por essa corrente, que tenha o condão de afastar completamente a qualidade de cidadão do ser humano, a fim de tratá-lo sem que esteja protegido por quaisquer das garantias conquistadas ao longo dos anos. 
Compreende-se, então, que a denominação de pessoa não é um conceito a ser apresentado pelo Estado, mas ser exposto pelo Direito inerente ao ser humano, que transcende a qualquer poder ou soberania estatal. Uma sociedade é formada por humanos, por pessoas (que se revestem de todos os direitos e garantias a elas inerentes); se um indivíduo pode deixar de ser considerado cidadão, logo uma sociedade pode deixar de assim ser considerada, e consequentemente, a humanidade pode afastar-se da tutela do Direitos. Dessa forma temos que esse discurso legitima o genocídio.

Sendo assim, com o fim das atrocidades ocorridas durante a segunda guerra mundial, outras as sucederam, outros massacres e outros conflitos armados. Com isso faz-se imprescindível que o reconhecimento do outro como um semelhante seráo que uniráos seres humanos como espécie.

Com a internacionalização dos Direitos Humanos, buscou-se a isonomia entre a espécie humana, a garantia de direitos comuns a todos os humanos, estejam eles acobertados ou não pelo manto de algum Estado.Dessa forma, ao retirarmos a cidadania de um "inimigo" a esse ainda restará os Direitos inerentes a pessoa humana.

A condição humana é o que une os seres humanos como espécie. A espécie humana é dotada de dualidade, o ser humano tem em si a tristeza e alegria, a sanidade e a loucura, o amor e o ódio, a inteligência e a debilidade, e essas dualidades o completam e convivem harmonicamente (MORIN, 2003).

Diante de todo o exposto, pode-se afirmar que a aplicação do Direito Penal do Inimigo mostra-se extremamente radical, isso pois grande parte dos Direitos Fundamentais seriam restringidos de forma absoluta a todo e qualquer ser humano, anulando os próprios fundamentos constitutivos da sociedade apresentados na Carta Magna

Ou seja, através da flexibilização de todas as garantias conquistadas ao longo dos séculos, estaria caracterizado um grande retrocesso. Pois o Estado Democrático de Direito foi uma conquista do ser humano concretizada por meio de diversas lutas travadas contra o poder soberano irrestrito. A alegação de que o Direito Penal do Inimigo traria maiores benefícios à sociedade, no que tange à proteção contra a criminalidade, deve ser visto com ressalvas, a fim de evitar distorções acerca da determinação dos indivíduos de uma dada sociedade.

Somos humanos, e temos em nós a dualidade, tornando o outro nosso inimigo pelo simples fato de delinquir, acaba-se por esquecer da condição humana, de forma que o ser humano acabara por tornar-se seu próprio inimigo. 


\section{REFERÊNCIAS}

ALMEIDA, Maria da Conceição Xavier de. A condição humana e a formação transdiciplinar. Trilhas Filosóficas, Caicó-RN, v. VII, n. 1, p. 77-92, jan.-jun. 2014.

ARENDT, Hannah. Entre o Passado e o Futuro. São Paulo: Perspectiva Universitária. 1972. Origens do totalitarismo: Antissemitismo, imperialismo, totalitarismo. São Paulo: Companhia de Bolso, 2012.

CASTRO, Flávia Lages de Castro. História do Direito Geral e Brasil. 4. ed. Rio de Janeiro: Lumen Juris, 2007.

COMPARATO, Fábio Konder. A afirmação histórica dos Direitos Humanos. 4. ed., rev. e atual. São Paulo: Saraiva, 2005.

DEMO, P. Metodologia do conhecimento científico. São Paulo: Atlas, 2000.

DOSTOIÉVSKY, Fiódor Mikhailovich. Crime e Castigo. Vol. I e II. Trad. Rosário Fusco. São Paulo: Abril, 2010.

FACHIN, Melina Girardi. Fundamentos dos direitos humanos: teoria e práxis na cultura da tolerância. Rio de Janeiro: Renovar, 2009.

FONSECA, J. J. S. Metodologia da pesquisa científica. Fortaleza: UEC, 2002.

GRECO, Rogério.Direito penal do equilíbrio: uma visão minimalista do direito penal. 6 . ed. Niterói: Impetus, 2011.

JAKOBS, Günther. MELIÁ, Manuel Cancio.Direito Penal do inimigo: noções e críticas.Org. e trad. André Luís Callegari, Nereu José Giacomolli. 2. Ed - Porto Alegre: Livraria do Advogado: 2007.

LAFER, Celso. A Reconstrução dos Direitos Humanos: um diálogo com o pensamento de Hannah Arendt. São Paulo: Companhia das Letras, 1998. 
Faculdades OPET. Curitiba PR - Brasil. Ano IV, nº 9, jan/jun 2013.

MORIN, Edgar, 1921- A cabeça bem-feita: repensar a reforma, reformar o pensamento / Edgar Morin; tradução Eloá Jacobina. - 8a ed. -Rio de Janeiro: Bertrand Brasil, 2003.

Os sete saberes necessários à educação do futuro. 2. ed. São Paulo : Cortez ; Brasília, DF : UNESCO, 2000.

PIOVESAN, A universalidade e a indivisibilidade dos direitos humanos: desafios e perspectivas. TST, Brasília, vol. 75, no 1, jan/mar, p. 107-113, 2009.

Direito Constitucional: Direitos Humanos e o Direito Constitucional

Internacional. Rio Grande do Sul: Escola da Magistratura do Tribunal Regional Federal da $4^{\mathrm{a}}$ Região, 2006. v. V

\section{CRIME AND PUNISHMENT: THE HUMAN BEING AS ENEMY}

Abstract:The theoryofthe Criminal Law oftheEnemyispresented in such a way as toavoidarguing it through a discussionaboutthehumanconditionandHumanRights, whichisdonethrough a bibliographicalreview. The humanbeing in breaking standards does notstrayfromhishumanity, for thedeviationisinherent in thespecies.

Keywords:Criminal Law. Humanrights. HumanCondition. 